This item was submitted to Loughborough's Research Repository by the author.

Items in Figshare are protected by copyright, with all rights reserved, unless otherwise indicated.

\title{
Body configuration in multiple somersault high bar dismounts
}

PLEASE CITE THE PUBLISHED VERSION

http://journals.humankinetics.com/

\section{PUBLISHER}

(c) Human Kinetics

VERSION

VoR (Version of Record)

LICENCE

CC BY-NC-ND 4.0

REPOSITORY RECORD

Kerwin, David G., Maurice R. Yeadon, and Sung-Cheol Lee. 2019. "Body Configuration in Multiple Somersault High Bar Dismounts". figshare. https://hdl.handle.net/2134/8641. 
This item was submitted to Loughborough's Institutional Repository (https://dspace.lboro.ac.uk/) by the author and is made available under the following Creative Commons Licence conditions.

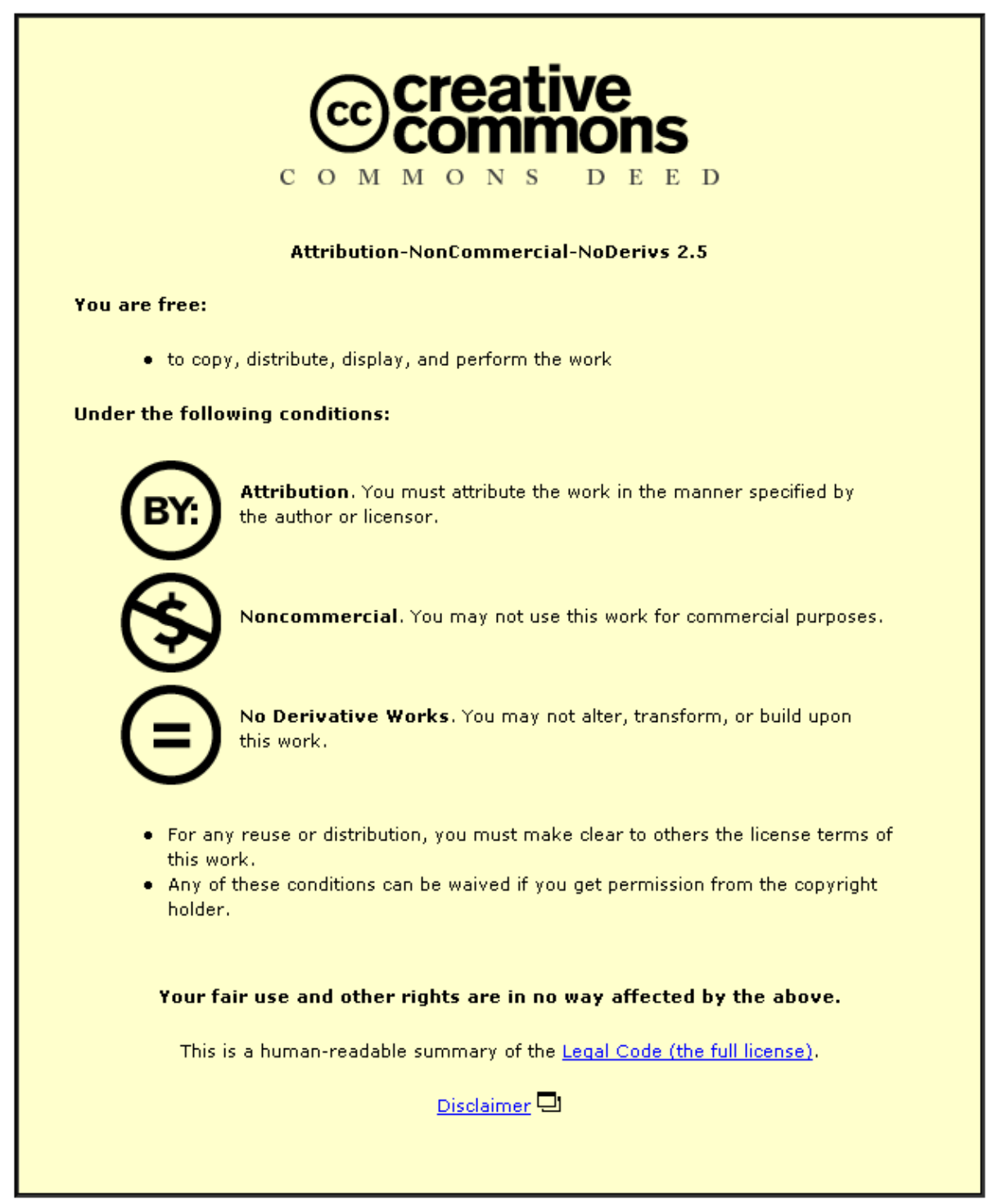

For the full text of this licence, please go to: http://creativecommons.org/licenses/by-nc-nd/2.5/ 


\title{
Body Configuration in Multiple Somersault High Bar Dismounts
}

\author{
David G. Kerwin, Maurice R. Yeadon, \\ and Sung-Cheol Lee
}

\begin{abstract}
An 11-segment three-dimensional simulation model was used to modify the body configurations of eight gymnasts performing multiple somersault dismounts during the Men's High Bar competition in the 1988 Seoul Olympic Games. Four layout double somersault performances were modified to change a characteristic backward arch to a straight body position. This modification reduced the somersault rotation by 0.03 to 0.10 somersaults. Four tucked triple somersault performances were modified so that the thigh abduction angle was reduced to zero. This modification resulted in underrotations ranging from 0.01 to 0.34 somersaults depending on the amount of thigh abduction in the original movement. The additional angular momentum needed for successful completion of the modified movements was small in general and in no case greater than $13 \%$.
\end{abstract}

A competitive gymnastic high bar routine comprises a series of circling movements culminating in a somersaulting dismount. Twisting somersault movements are common, but two popular and demanding nontwisting multiple somersaults are regularly performed by international gymnasts. Nissinen, Preiss, and Brüggemann (1985) used a two-dimensional simulation model to demonstrate that given the takeoff conditions for a straight double somersault, the same gymnast would be able to perform a tucked triple somersault dismount. The single gymnast analyzed adopted an arched body shape in the double somersault dismount but generated sufficient angular momentum to complete the tucked triple somersault.

The dismounts used by the eight finalists in the Men's High Bar competition at the 24th Olympiad in Seoul in 1988 comprised four straight double somersaults, two tucked triple somersaults, and two multiple somersaults with twist. Of the 12 gymnasts who used the tucked triple somersault, only the two finalists performed the skill with their knees close together. The remainder performed the

D.G. Kerwin is with the Biomechanics Laboratory, Dept. of P.E. and Sport Science, Loughborough University, Loughborough, Leics. LE11 3TU, U.K. Sung-Cheol Lee is with the Dept. of P.E. at Yonsei University, Seoul, S. Korea. M.R. Yeadon is with the Biomechanics Laboratory at Loughborough University and the Biomechanics Laboratory at the University of Calgary, Calgary, Alberta, Canada T2N 1 N4. 
movement in a "split-tucked" position, with the thighs abducted to reduce the moment of inertia about the somersault axis. These gymnasts may have had insufficient somersault momentum so that they needed to split during the flight phase to complete the rotations before landing. In this case more angular momentum or more flight time would be required to enable the tuck to be closed. Alternatively these competitors may have habituated the splitting action and could have improved their form marks by keeping the knees together while still achieving the desired rotation.

The four gymnasts who used the straight double somersault dismount released the bar while in a piked position and moved into a back arched shape for most of the flight phase before re-piking in preparation for landing. Although spinal hyperextension was symptomatic of these four elite competitors, the question arises as to whether arching was necessary or whether sufficient angular momentum had been generated to permit the movement to be completed in a true straight body position. This paper attempts to answer these questions through the use of three-dimensional computer simulation.

\section{Data Collection}

\section{Methods}

Two Photosonics 1PL 16-mm cine cameras were used to record the high bar dismounts during competition on September 20, 22, and 24 at the 24th Olympiad in Seoul, 1988. From the twin camera records of the "team," "'individual all around,' and "'apparatus final" competitions, eight performances were selected for analysis. Four were tucked triple somersaults and four were straight double somersaults. Only subjects performing a controlled landing from the dismount were considered. The two best tucked triple somersaults performed by the finalists over the 5-day period were selected. Two triple somersault dismounts that used the split-tuck technique were also chosen. The four selected straight double somersaults comprised two from the high bar finalists and two from the remaining competitors on the other days of competition. The triple somersault group was composed of gymnasts from China, East Germany, the Soviet Union, and the United States while the double somersault group comprised gymnasts from Canada, China, the Soviet Union, and the United States.

The dismounts were filmed at $70 \mathrm{~Hz}$ with a $160^{\circ}$ shutter, using an aperture of 4.0 with the cameras placed at surveyed positions 40 meters from the high bar and 11 meters above the landing surface. One camera was located to the side of the apparatus in the vertical plane containing the high bar, and the other was in the perpendicular vertical plane through one of the supporting uprights. The field of view from each camera was approximately $8 \mathrm{~m}$ wide.

Prior to the competition, 35-mm slides were taken of the seven members of the Canadian Team to give front and side views from which anthropometric data could be obtained on a variety of gymnast physiques for the purpose of calculating segmental inertia parameters.

\section{Data Analysis}

All sequences were digitized using a TDS HR48 tablet linked to a microcomputer (Acorn BBC/128k). Two known points on one of the high bar uprights were digitized for calibration purposes. In each film frame the wrist, elbow, shoulder, hip, 
knee, and ankle centers were digitized. The resulting two film data sets were synchronized in time by matching the paths traced by the center of mass of the body at takeoff and landing (Yeadon, 1989). The 3-D coordinates of the 12 body landmarks were reconstructed from the digitized data (Yeadon, 1989), and angles describing body configuration and orientation were determined (Yeadon, 1990a). The somersault orientation angle was defined by the line joining the mid-shoulders to mid-knees. This procedure minimizes the effects that configurational changes produce in the calculated somersault angle (Yeadon, 1990c).

Inertia values were generated by digitizing $35-\mathrm{mm}$ slide images of the seven Canadian Team members and using the model of Yeadon (1990b). For Competitor 112 there was a direct match. For other competitors the inertia set that minimized the variance of the angular momentum of the body about its mass center during flight was selected as the closest match (Yeadon, 1990c).

Flight time was calculated from the vertical motion of the gymnast's center of mass assuming a constant acceleration of $9.81 \mathrm{~ms}-2$. Angular momentum data were generated for each of the eight selected multiple somersault performances and were normalized for each film sequence to give the equivalent number of straight somersault rotations per unit flight time. The use of straight somersault units rather than the usual moment-of-inertia units permits the direct comparison of gymnasts with different physiques. Using the time of flight as the unit of time is equivalent to integrating the angular momentum, and this permits the comparison of dismounts with different flight times.

An 11-segment computer model of aerial movement was used to simulate each dismount, and the level of agreement between simulation and film was determined (Yeadon, Atha, \& Hales, 1990). The calculated angular momentum and body configuration time history were used as input for each simulation. The body configurations were modified and the corresponding changes in the somersault angles were determined using simulations based on the modified input.

In the straight double somersaults, the hip angle between the gymnast's trunk and thighs was altered during the midflight phase. For the first $10 \%$ and last $20 \%$ of the flight phase, the hip angle matched the film data. Between the 20 and $70 \%$ points of the flight, the hip angle was fixed at $180^{\circ}$ to give straight body alignment. The transitions between 10 and $20 \%$ and between 70 and $80 \%$ were made continuously and smoothly so that endpoint angles and velocities matched. In the midflight phase the knee angles were also set to $180^{\circ}$.

For the triple somersaults, body configuration matched the film data at the beginning and end of the flight phase. The tucked position was altered, by changing the thigh abduction angle, so that the knees were together during the central $80 \%$ of the motion.

\section{Results and Discussion}

Table 1 summarizes the flight characteristics of the two types of somersault. The height of the whole body mass center was calculated relative to the landing surface, which was $2.55 \mathrm{~m}$ below the bar. The mean flight time for the triple somersaults was 0.06 seconds longer than that for the double somersaults. There was an overlap between the groups, with Competitor 149 performing the triple somersault in the same time that Competitor 198 took to execute the double. In all cases the maximum heights attained in the triple somersault dismounts were higher than those 
Table 1

Comparisons Between Double and Triple Somersault Dismounts

\begin{tabular}{lccccc}
\hline Competitor & Saltos & $\begin{array}{c}\text { Angular } \\
\text { momentum }\end{array}$ & $\begin{array}{c}\text { Flight } \\
\text { time (s) }\end{array}$ & $\begin{array}{c}\text { Release } \\
\text { height (m) }\end{array}$ & $\begin{array}{c}\text { Maximum } \\
\text { height (m) }\end{array}$ \\
\hline 112 & 2 & 1.57 & 1.23 & 2.07 & 3.45 \\
122 & 2 & 1.41 & 1.26 & 2.59 & 3.73 \\
189 & 2 & 1.47 & 1.25 & 2.54 & 3.69 \\
198 & 2 & 1.68 & 1.28 & 2.34 & 3.68 \\
$M$ & & 1.53 & 1.26 & 2.39 & 3.63 \\
$S D$ & & 0.12 & 0.02 & 0.24 & 0.13 \\
120 & 3 & 1.23 & 1.29 & 2.57 & 3.89 \\
149 & 3 & 1.43 & 1.28 & 2.76 & 3.95 \\
193 & 3 & 1.19 & 1.34 & 2.67 & 4.08 \\
202 & 3 & 1.27 & 1.37 & 2.46 & 4.03 \\
$M$ & & 1.28 & 1.32 & 2.62 & 3.99 \\
$S D$ & & 0.11 & 0.04 & 0.13 & 0.08 \\
\hline
\end{tabular}

*Straight somersaults per unit flight time.

achieved in the doubles. Allowing for the fact that there was a mean difference of $0.23 \mathrm{~m}$ in release height, the difference between the maximum heights attained in the two types of dismount was a clear indication of higher release velocities for the triple somersaults.

The normalized somersault angular momentum values for the double somersaults ranged from 1.41 to 1.68 , with a mean of 1.53 straight somersaults per unit flight time. The range of values for the triple somersaults was from 1.19 to 1.43 , with a mean of 1.28 straight somersaults per unit flight time. The ratio of mean normalized angular momentum values for the two types of somersault was 1.20 , which became 1.26 when the angular momenta were expressed in straight somersaults per second.

Although the triple somersaults had longer flight times than the straight double somersaults, the angular momentum values were generally lower. These data extend the findings of Nissinen et al. (1985), showing that the angular momentum generated for a straight double somersault was more than sufficient to perform a tucked triple somersault.

Table 2 summarizes the results from the straight double somersault simulations. The somersault values, expressed in revolutions, show that there was close agreement between the total rotation calculated from film data and the corresponding values obtained from the simulations. The maximum differences between film and simulation values were less than 0.04 somersaults in each of the four double somersault dismounts. The third somersault column contains the simulation output following modifications to the hip and knee angles during the midflight phase. The hip angles were modified to give a straight rather than a back arched position for one somersault. The change in somersault angle, shown in the fourth 
Table 2

Rotation in Straight Double Somersault Dismounts

\begin{tabular}{llllll}
\hline \multicolumn{7}{c}{ Somersault (revolutions) } & & \\
Competitor & Film & Sim. & Mod. & \% Change & $\begin{array}{c}\text { Minimum hip } \\
\text { abduction }\end{array}$ \\
\hline 112 & 1.67 & 1.67 & 1.57 & -5.8 & $124^{\circ}$ \\
122 & 1.56 & 1.56 & 1.47 & -5.7 & $115^{\circ}$ \\
189 & 1.57 & 1.57 & 1.50 & -4.8 & $115^{\circ}$ \\
198 & 1.66 & 1.66 & 1.63 & -1.5 & $128^{\circ}$ \\
\hline
\end{tabular}

column, has been expressed as a percentage of the unmodified simulation rotation, showing that the effect of straightening the body would reduce the somersault by approximately 5-6\% for three of the four competitors and by $1.5 \%$ for Competitor 198, who had the greatest angular momentum. These reductions arose almost entirely from the changes in the hip angles since the effect produced by straightening the knees was minimal. The minimum hip angle reported in the final column refers to the minimum angle between trunk and thighs prior to modification. In each case this was during hyperextension, resulting in a backward arch of approximately $120^{\circ}$.

Figure 1 shows the changes in the whole-body moment of inertia about a lateral axis through the center of mass for the straight double somersault of Competitor 112. Moment of inertia values have been normalized with respect to a straight body configuration in which the arms are by the sides. The squares show the moment of inertia values for the configurations obtained from the film data. The continuous line shows the moment of inertia values for the modified configurations in which the hips and knees are extended between the 20 and $70 \%$ points of the flight. For the first $10 \%$ and the last $20 \%$ of the flight, the configurations are identical. Since the modified configuration has larger moment of inertia values during midflight, the angular velocity values of the corresponding simulation are smaller in order for the angular momentum to remain constant. As a consequence the total rotation in the modified simulation is less than that in the actual dismount.

Figure 2 depicts computer-generated sequences of the dismounts of Gymnasts 198 and 112. All four competitors released the bar in a dished shape with the shoulders, hips, and knees slightly flexed. Competitors 202 and 120 adopted the same early arch as that shown by Competitor 112 in Figure 2. Competitor 198 progressed more slowly through a straight position and remained straighter, as shown in Figure 2.

Figure 3 compares the somersault values obtained from simulation and film for the triple somersault dismount of Competitor 193. The maximum deviations between simulation and film were less than 0.04 somersaults for each of the four triple somersault dismounts.

Table 3 presents analysis data for the triple somersault dismounts. The final column contains thigh abduction angles describing the maximum value through which each gymnast had abducted the thighs in the midflight phase. Com- 
normalized moment of inertia

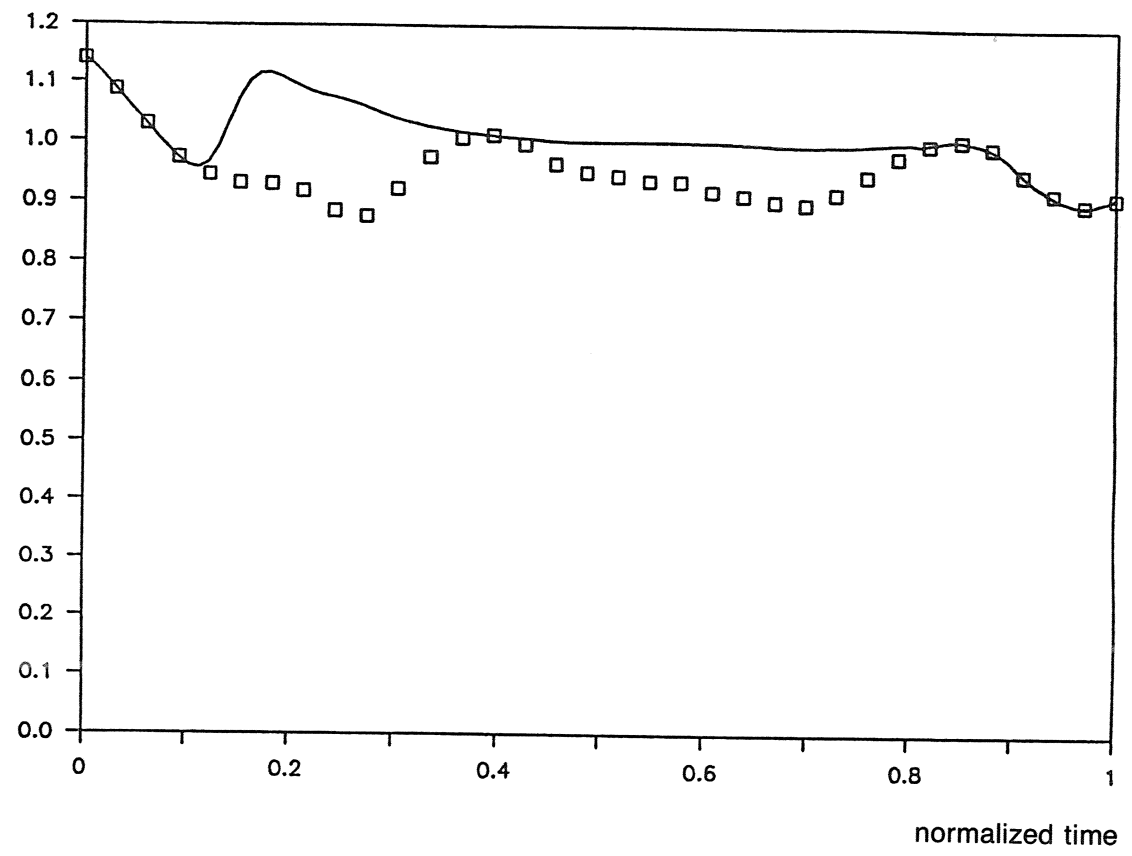

Figure 1 - Normalized moment of inertia values for a straight double somersault dismount from film data (squares) and modified data (continuous line).

petitors 149 and 193 were the finalists who performed the somersaults in a traditional tucked position, maintaining a thigh abduction angle of $6^{\circ}$ or less for the first complete somersault. The simulation sequence of Competitor 149 illustrates this characteristic in Figure 4. The maximum thigh abduction angles for Competitors 149 and 193, reported in Table 3 as $12^{\circ}$ and $16^{\circ}$, were attained during the final somersault prior to landing. The thigh angles of $26^{\circ}$ and $46^{\circ}$ for Competitors 202 and 120 occurred in midflight and clearly identify these gymnasts as using the split-tuck technique. Each of these two competitors abducted the thighs by at least half the maximum angle during the first half somersault and continued to widen the split during the next somersault.

Figure 4 shows a computer-generated front view of the sequence for Competitor 120 that illustrates this pattern. In the final rotation, the thigh abduction angles were reduced to values of less than $10^{\circ}$ in preparation for landing.

By preserving the takeoff and landing configurations but reducing the thigh abduction angles to zero in the midflight phase, the effect of using a closed tuck rather than a split-tuck was determined. The reduction in somersault rotation was expressed as a percentage of the unmodified simulation somersault rotation. For 

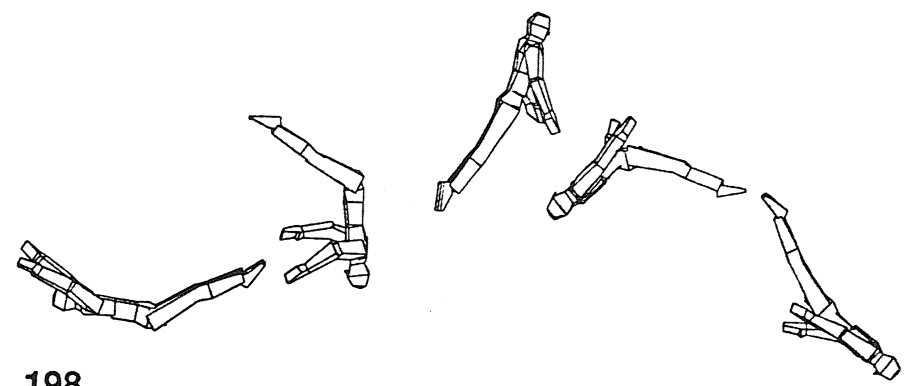

198

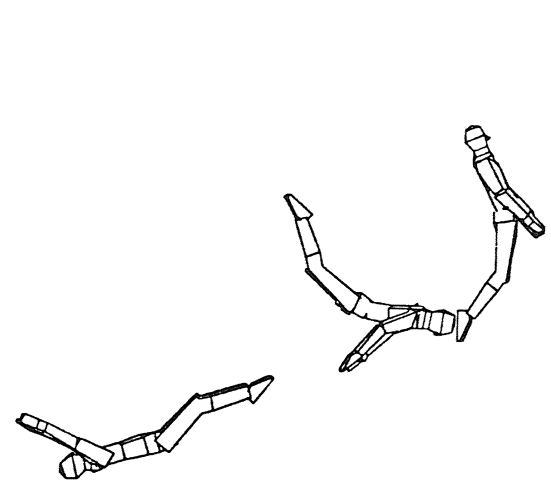

112
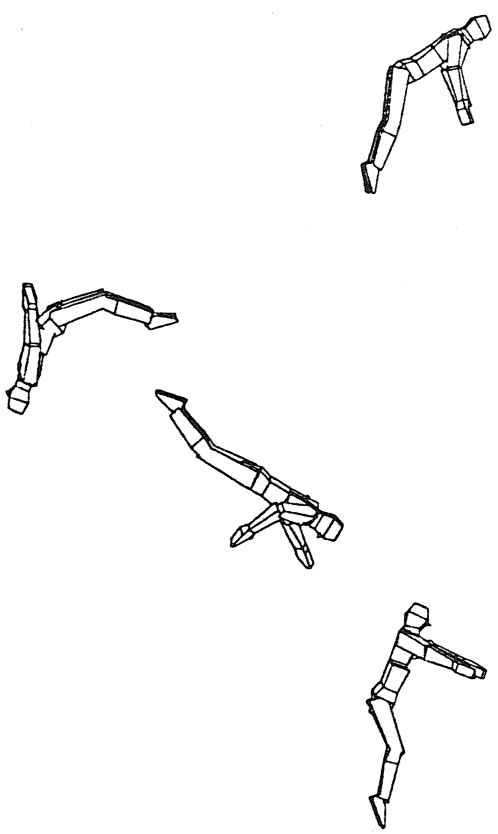

Figure 2 - Graphics sequences of straight double somersault dismounts.

Competitors 193 and 149 the value of $-0.2 \%$ indicated a very small change of less than $2^{\circ}$ of somersault. For Competitor 202 the reduction of $2.0 \%$ represented a reduction of about $19^{\circ}$ in somersault rotation, and for Competitor 120 the large $13.0 \%$ reduction would have meant an underrotation of one third of a somersault.

It should be noted that these underrotations occur because the whole-body moment of inertia is larger when the thighs are adducted since the angle between thigh and trunk is kept constant. If a tighter tucked position were used, it would still be possible to complete the required rotation. This can be seen by comparing the angular momenta values of Competitors 120 and 193 shown in Table 1. Com- 
somersault

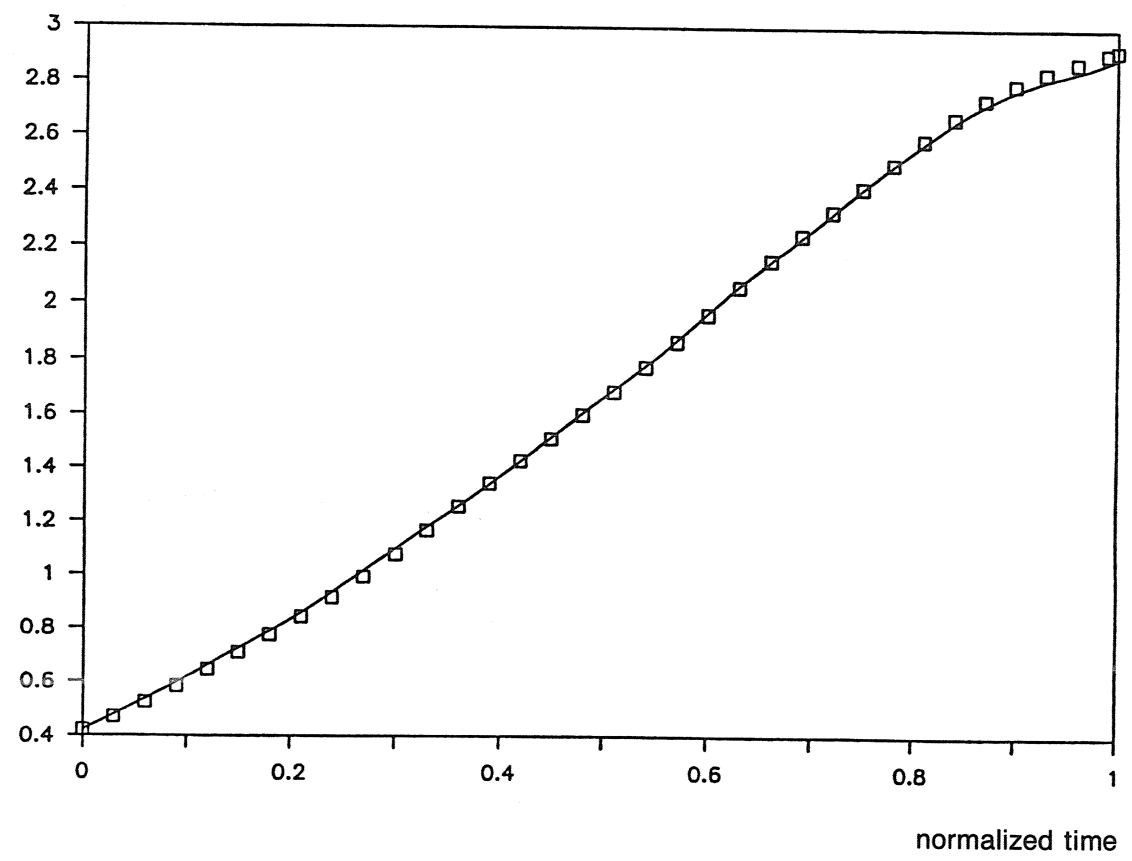

Figure 3 - Somersault values from simulation (continuous line) and film (squares).

Table 3

Rotation in Tucked Triple Somersault Dismounts

\begin{tabular}{|c|c|c|c|c|c|}
\hline \multirow[b]{2}{*}{ Competitor } & \multicolumn{3}{|c|}{ Somersault (revolutions) } & \multirow[b]{2}{*}{$\%$ Change } & \multirow[b]{2}{*}{$\begin{array}{l}\text { Maximum thigh } \\
\text { abduction }\end{array}$} \\
\hline & Film & Sim. & Mod. & & \\
\hline 120 & 2.61 & 2.59 & 2.25 & -13.0 & $46^{\circ}$ \\
\hline 149 & 2.52 & 2.50 & 2.50 & -0.2 & $12^{\circ}$ \\
\hline 193 & 2.54 & 2.52 & 2.50 & -0.2 & $16^{\circ}$ \\
\hline 202 & 2.55 & 2.54 & 2.48 & -0.2 & $26^{\circ}$ \\
\hline
\end{tabular}



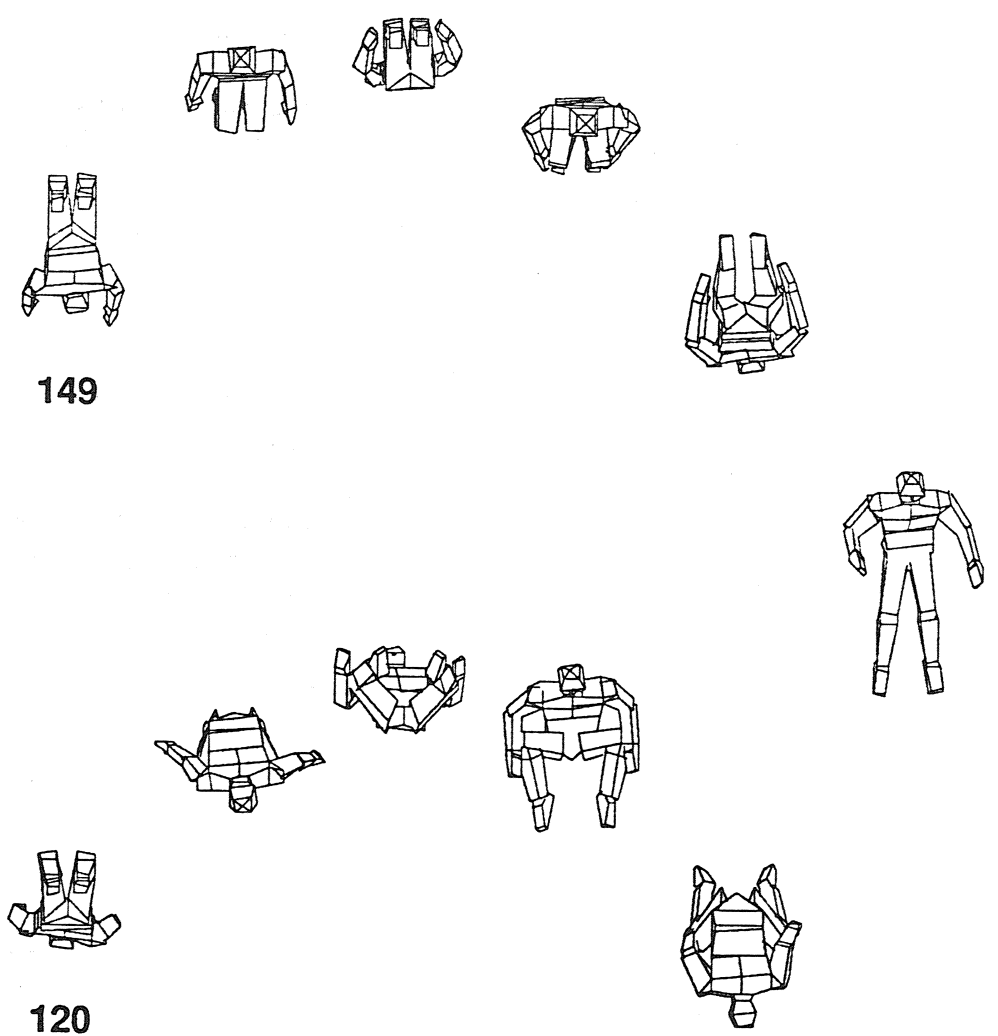

120

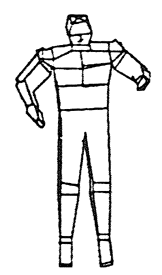

Figure 4 - Graphics sequences of tucked triple somersault dismounts.

petitor 120 used a split-tuck and had a normalized angular momentum value of 1.23 straight somersaults per flight time while Competitor 193 used a closed tuck and had a smaller angular momentum value of 1.19. Thus Competitor 120 did not need to use a split-tuck in order to complete the movement. 


\section{Summary and Conclusions}

In general, gymnasts performing the tucked triple somersault made their release with their center of mass in a higher position, traveled to a greater vertical height, and were in flight longer than gymnasts who performed the straight double somersault dismount. The mean normalized angular momentum of the tucked triple somersaults was $16 \%$ lower than that of the straight double somersaults. Adopting a straight body position during the midflight phase of the double somersaults resulted in underrotations of between 0.03 and 0.10 somersaults.

Complete adduction of the thighs during the triple somersault dismounts reduced the rotation of the two closed tucked triples by less than 0.01 somersaults. The corresponding modification to the two gymnasts using the split-tuck technique resulted in underrotations of 0.06 and 0.34 somersaults. These underrotations could have been compensated for by adopting a tight closed tuck configuration rather than by using a split-tuck.

In order to perform the dismounts in a technically correct manner, all gymnasts could benefit from larger angular momentum values. Then they could show a stretched body position in the double somersaults and could perform a triple somersault in a tucked position with knees together, followed by an early kickout to assist in controlling the rotation on landing.

\section{References}

Nissinen, M., Preiss, R., \& Brüggemann, P. (1985). Simulation of human airborne movements on the horizontal bar. In D.A. Winter, R.W. Norman, R.P. Wells, K.C. Hayes, \& A.E. Patla (Eds.), Biomechanics IX-B (pp. 373-376). Champaign, IL: Human Kinetics.

Yeadon, M.R. (1989). A method for three-dimensional analysis of ski jumping using panning cameras. International Journal of Sport Biomechanics, 5, 238-247.

Yeadon, M.R. (1990a). The simulation of aerial movement. Part I: The determination of orientation angles from film data. Journal of Biomechanics, 23, 59-66.

Yeadon, M.R. (1990b). The simulation of aerial movement. Part II: A mathematical inertia model of the human body. Journal of Biomechanics, 23, 67-74.

Yeadon, M.R. (1990c). The simulation of aerial movement. Part III: The determination of the angular momentum of the human body. Journal of Biomechanics, 23, 75-83.

Yeadon, M.R., Atha, J., \& Hales, F.D. (1990). The simulation of aerial movement. Part IV: A computer simulation model. Journal of Biomechanics, 23, 85-89.

\section{Acknowledgment}

The support provided by the International Olympic Committee Medical Commission and the Sport Canada Applied Research Program is gratefully acknowledged. 